EDITORIAL

\title{
Épocas de desastres epidemiológicos y ecológicos, épocas de innovación y renovación
}

\author{
Epidemiological and ecological disaster times, times of innovation and renewal
}

En Honduras, estamos finalizando el año 2020 en medio de una crisis epidemiológica por la pandemia de COVID-19 y una crisis ecológica por dos huracanes y tormentas tropicales; ambas con efectos e impacto negativos de gran dimensión sobre la población, determinantes de la salud y el desarrollo socioeconómico. ${ }^{1,2}$ La Revista Médica Hondureña, con su vida editorial de 90 años, registra para la historia estos eventos y su contexto evolutivo (https://revistamedicahondurena.hn/, http:// www.bvs.hn/RMH/htm|5/\#gsc.tab=0).

A nueve meses de pandemia, en el mundo se han informado $72,641,016$ casos y 1,618,882 muertes por COVID-19. ${ }^{2}$ Honduras ha informado 114,043 casos y 2,974 muertes. Las tasas de 11,433 casos y 298 muertes por millón de habitantes, son mayores que las registradas por Guatemala y El Salvador y menores que las registradas por Costa Rica, Panamá y República Dominicana; aunque la tasa de pruebas de laboratorio de 28,471 por millón de habitantes es inferior a la registrada por todos los países de la subregión, los cuales registran tasas desde 1.1 (Guatemala) hasta 8.6 (Panamá) veces mayores. ${ }^{3}$ Por otra parte, los fenómenos naturales Eta e lota, que afectaron el país en las primeras dos semanas del mes de noviembre, produjeron extensos daños en la infraestructura. Según OPS/OMS, ${ }^{4}$ más de 400 establecimientos de salud reportaron daños, al menos 120 están inoperantes, 27 se derrumbaron y 12 reportaron daños en el equipo de la cadena de frío. Asimismo, se estimó que estos daños en infraestructura sanitaria produjeron que aproximadamente 2 millones de personas se encuentren con acceso limitado o sin acceso a los establecimientos de salud y que en al menos 500,000 de estas personas existen necesidades de salud cuya atención no puede postergarse.

En estas circunstancias, con múltiples obstáculos, retos y desafíos, también surgen oportunidades para la innovación y la renovación; estas pueden presentarse a todos los niveles, desde las comunidades hasta las instituciones, personas y grupos, brindando la posibilidad de soluciones. ${ }^{5}$ En este periodo difícil, la Revista ha realizado importantes avances para alcanzar parámetros bibliométricos de calidad, especialmente la puntualidad y el importante logro de la inclusión de 4-6 artículos originales por número, en los últimos números publicados, bajo criterios de ética y de calidad. Los artículos del presente número reflejan diferentes aspectos clínicos, epidemiológicos e históricos del país y en el actual contexto de la pandemia de COVID-19. El artículo original sobre infraestructura sanitaria describe las barreras de acceso para las personas con discapacidad, pero también refleja las limitaciones para todos los usuarios y el personal de salud en tiempos de la pandemia (pág. 70). El artículo especial sobre la preparación de los hospitales presenta una revisión de las estrategias consensuadas y recomendadas para responder ante la pandemia (pág. 127). El artículo de historia de la medicina sobre la epidemia de viruela nos lleva a la reflexión ante situaciones similares en la Tegucigalpa de hace más de 200 años (pág. 121). También hay dos artículos de investigación; uno que escudriña la investigación desde las publicaciones en la Revista (pág. 92) y otro que utilizando métodos mixtos identificó las prioridades de investigación en el contexto de la pandemia en América Latina y el Caribe (pág. 84).

El Consejo Editorial cierra este año con la consternación resultante por las pérdidas que afrontamos; sin embargo, también con la satisfacción de haber avanzado la Revista en los parámetros necesarios para adherirse a bases de datos internacionales. Especialmente, despedimos el año con la convicción que mejores tiempos para todos, están por venir.

Jackeline Alger, MD, PhD

Directora

Revista Médica Hondureña

\section{REFERENCIAS}

1. Despacho de Comunicaciones y Estrategia Presidencial (HN). Coronavirus COVID-19 en Honduras. [Internet]. Tegucigalpa: Despacho de Comunicaciones y Estrategia Presidencial; 2020. [consultado 13 diciembre 2020]. Disponible en: https://covid19honduras.org/

2. United Nations Office for the Coordination of Humanitarian Affairs. Latin America \& the Caribbean. In Honduras, clinging to hope for a new start after two hurricanes. N.Y.: OCHA; 2020. [consultado 14 diciembre 2020]. Disponible en: https://www.unocha.org/story/honduras-clinging-hopenew-start-after-two-hurricanes

3. Worldometer. COVID-19 Coronavirus pandemic. [Internet]. S.I: worldometer; 2020. [consultado 13 diciembre 2020]. Disponible en: https://www. worldometers.info/coronavirus/

4. United Nations Office for the Coordination of Humanitarian Affairs. Latin America \& the Caribbean. Weekly Situation Update (30 November - 6 December 2020), 7 December 2020. N.Y.: OCHA; 2020. [consultado 14 diciembre 2020]. Disponible en: Latin America \& the Caribbean: Weekly Situation Update (30 November - 6 December 2020) (reliefweb.int)

5. Halpaap BM, Tucker JD, Mathanga D, Juban N, Awor P, Saravia NG, et al. Social innovation in global health: sparking location action. Lancet Glob Health. 2020;8(5):e633-e634. 